\title{
Food Additives and Food Processing Aids: The Role, Function And Future Research Need of Industrial Food Biotechnology
}

Melaku Tafese Awulachew*

Food Science and Nutrition Research, Ethiopian Institute of Agricultural Research, Addis Ababa, Ethiopia.

Abstract

Biotechnology is a branch of science concerned with the utilization of various living organisms in the creation of useful products. Food biotechnology provides better resource utilization rate and reduces environmental pollution by treating food processing wastes through fermentation and enzymatic engineering. Food processing as an aspect of biotechnology targets the selection and improvement of microbes. The essence is to improve the process of enhancing efficiency, quality, safety, and consistency of bioprocessed products. In recent years, the application has been observed in the fields of flavor alteration, food additives, and the development of a wide range of value-added products. Industrial food biotechnology has ushered in significant improvements in food processing, is flavor enhancement and vaccine development, allowing for the creation of goods with increased shelf life and nutritional value.Oxidants/reductants, emulsifiers, hydrocolloids, colorants, and preservatives were the most commonly utilized additions. Enzymes, Free Flowing Agents, and antifoams are the most common processing aids.Food additives are used either to facilitate or complement a wide variety of production methods in the modern food supply and whereas, a processing aid is a substance used in the production of processed food, and which may end up in the finished product, but which is not required to be labeled on the food product. Food processing aid as a substance that is used for a technical effect during food processing or manufacture/facilitating the production process but, unlike food additives, its use does not affect the intrinsic characteristics of the food and it results in no or negligible residues of the substance or its by-products in or on the finished food.

Keywords: Biotechnology; Food Additives; Food Processing Aids; Food Processing; Future Research Need.

\section{Introduction}

The role of industrial food biotechnology in food industry has a wide range of technologies that are being used for food processing in several countries in the world especially in developing countries. Among such technologies are dehydration, dying, freezing, canning, vacuum packing, sugar crystallization, enzyme production, probiotics, and osmo-dehydration to mention but a few. Through domestication and agricultural activities of breeding and selection of plants, new food crops that permit fabrication of safer, healthier, tastier, nutritional, and edible food items were developed [14].

Food biotechnology provides better resource utilization rate and reduces environmental pollution by treating food processing wastes through fermentation and enzymatic engineering. Food processing as an aspect of biotechnology targets the selection and improvement of microbes. The essence is to improve the process of enhancing efficiency, quality, safety, and consistency of bioprocessed products [20]. The process uses various biotechnological tools and technologies to transform perishable raw ingredients or inedible raw food materials into more palatable foods, useful shelf stable with long shelf life and potable beverages [18]. Through the use of modern biotechnology in the food industry, reduction of food losses has not only made possible, but the efficiency of food quality has also been improved.

Food additives are defined in European legislation as "any substance not normally consumed as a food in itself and not normally used as a characteristic ingredient of food, whether or not it has nutritive value, the intentional addition of which to a food for a technological purpose in the manufacture, processing, prepa-

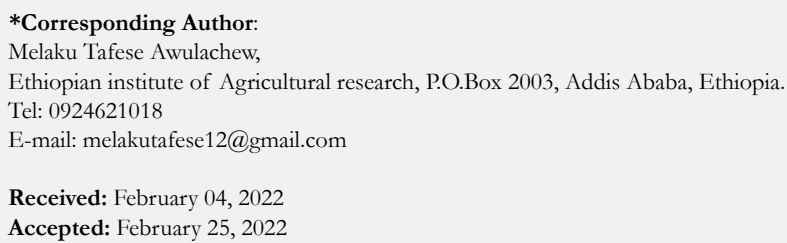

Citation: Melaku Tafese Awulachew. Food Additives and Food Processing Aids: The Role, Function And Future Research Need of Industrial Food Biotechnology. Int J Med Biotecbnol Genetics. 2022;8(11):73-82. doi: http://dx.doi.org/10.19070/2379-1020-2200012

Copyright: Melaku Tafese Awulachew 2022. This is an open-access article distributed under the terms of the Creative Commons Attribution License, which permits unrestricted use, distribution and reproduction in any medium, provided the original author and source are credited. 
ration, treatment, packaging, transport or storage of such food results, or may be reasonably expected to result, in it or its byproducts becoming directly or indirectly a component of such foods"( Directive 89/107/EEC,1989;[2, 12].

Food additives are used either to facilitate or complement a wide variety of production methods in the modern food supply. Their two most basic functions are that they either make food safer by preserving it from bacteria and preventing oxidation and other chemical changes, or they make food look or taste better or feel more pleasing in the mouth. The use of additives in food preservation is, not surprisingly, one of the oldest traditions. Our for bears may not have thought of saltpetre, used as a curing agent, or vinegar (acetic acid) as additives, but they would have been the mainstay for ensuring a longer-term supply of precious perishable foods. Salt, though not an additive by the modern definition, was the other essential.

Food additives known as the additives "framework" Directive, this Directive also defines processing aids as "any substance not consumed as a food ingredient by itself, intentionally used in the processing of raw materials, foods or their ingredients, to fulfil a certain technological purpose during treatment or processing, and which may result in the unintentional but technically unavoidable presence of residues of the substance or its derivatives in the final product, provided that these residues do not present any health risk and do not have any technological effect on the finished product."

A processing aid is a substance that assists in certain technical aspects of food production in the manufacturing process. Specific examples of processing aids include antimicrobial agents used in meat processing, filter aids to process oils and beverages, and enzymes to enhance bread dough functionality. Processing aids are generally not required to be declared as an ingredient on a food packaging label, although use of a processing aid that contains a priority allergen or has animal origins may require proper labeling as to not inadvertently expose individuals with dietary restrictions to such substances [3]. Since it is not always practical or possible to remove the processing aid after it accomplishes its intended purpose, the CAC acknowledges that use of a processing aid can unintentionally introduce a "residue" into the final processed material [22]. Because of this possible unintentional introduction of chemical components, it is important to understand the downstream effects of using a processing aid and to determine the concentrations of any substances remaining in the food from processing. Therefore, the objective of this review paper is to overview the role of Industrial Food Biotechnology for food additives and food processing aids.

\section{Food Additives In Industrial Food Biotechnology: An Overview}

\section{Roles of food additives}

Food additives play a vital role in today's food supply. They allow the people to have a variety of foods year-round. And, they make possible an array of convenience foods without the inconvenience of daily shopping. Food additives perform a variety of useful functions in foods that are often taken for granted. Since, most people no longer live on farms, additives help keep food whole- some and appealing while route to markets sometimes thousands of miles away from where it is grown or manufactured. Additives also improve the nutritional value of certain foods and can make them more appealing by improving their taste, texture, consistency or colour [23].

\section{Food additives and their functions}

The different group of food additives are sweeteners, coloring agents, preservatives, emulsifiers, stabilisers, thickeners, flavour enhancers and miscellaneous [16]. Depending on the technological purpose that the particular additive is intended to have in the food to which it is added, they are further classified in to several functional groups.

Preservatives: Preservatives are probably the single most important class of additives, as they play an important role in the safety of the food supply. Despite this fact, any chemical used to counteract the perishability of food raw materials has often become perceived as suspect, and any food containing a preservative has been considered inferior or unsafe. Yet the use of chemical preservatives, such as sulphur dioxide and sulphites, is but a continuation of the age-old practices of using salt, sulphite and spices to preserve perishable foods in the days before refrigeration and modern processing techniques. All food raw materials are subject to biochemical processes and microbiological action, which limit their keeping qualities. Preservatives are used to extend the shelf-life of certain products and ensure their safety through that extended period. Most importantly, they retard bacterial degradation, which can lead to the production of toxins and cause food poisoning [17]. Thus, they offer a clear consumer benefit in keeping food safe over the shelf-life of the product, which itself may be extended by their use and thus meet the demands of modern lifestyles, including infrequent bulk shopping expeditions [12]. The continued perception of preservatives as undesirable, to which the many labels protesting "no artificial preservatives" testify, is therefore an unfortunate consumer misapprehension.

Antioxidants: Antioxidants reduce the oxidative deterioration that leads to rancidity, loss of flavour, colour and nutritive value of foodstuffs. Fats, oils, flavouring substances, vitamins and colours can all oxidise spontaneously with oxygen when exposed to air [6]. The rate of deterioration can vary considerably and is influenced by the presence of natural antioxidants and other components, availability of oxygen, and sensitivity of the substance to oxidation, temperature and light, for example. Oxidation can be avoided, or retarded, by a number of means, such as replacing air by inert packaging gases, removal of oxygen with glucose oxidase, incorporation of UV-absorbing substances in transparent packaging materials, cooling, and use of sequestering agents. These may not be possible in all cases, or sufficient for an adequate shelf-life for some foods. Thus, antioxidants are used to retard oxidative deterioration and extend shelf-life. Some antioxidants actually remove oxygen by self-oxidation, e.g., ascorbic acid, whilst others interfere in the mechanism of oxidation; tocopherols, gallic acid esters, BHA and BHT. All have specific properties, making them more effective in some applications than in others.

Often a combination of two or more antioxidants is more effective than any one used simply because of their synergistic effects [8]. The presence of sequestering agents, such as citric acid, may also have a synergistic effect, by reducing the availability of me- 
tallic ions that may catalyse oxidation reactions. The use of the powerful synthetic antioxidants BHA, BHT and the gallic acid esters is very restricted. Tocopherols, which can be either natural or synthetic, are less restricted but are less effective in the protection of processed foods. Antioxidants cannot restore oxidised food; they can only retard the oxidation process. As oxidation is a chain reaction process, it needs to be regarded as early as possible. The most effective use of antioxidants is therefore in the fats and oils used in the manufacturing process.

Emulsifiers and stabilisers: The purpose of emulsifiers and stabilisers is to facilitate the mixing together of ingredients that normally would not mix, namely fat and water. This mixing of the aqueous and lipid phases is then maintained by stabilisers. These additives are essential in the production of mayonnaise, chocolate, ice cream, homogenized milk products and fat spreads [25]. The manufacture of fat spreads (reduced-fat substitutes for butter and margarine), has made a significant contribution to consumer choice and dietary change, and would not be possible without the use of emulsifiers and stabilisers. Other reduced- and lowfat versions of a number of products are similarly dependent on this technology. Anyone who has ever made an emulsified sauce, such as mayonnaise or hollandaise, will appreciate the benefits of this technology - still more so those who have failed miserably in the technique and ended up with an expensive mess of curdled ingredients!

In addition to this function, the term stabilizer is also used for substances that can stabilize, retain or intensify an existing colour of a foodstuff and substances that increase the binding capacity of the food to allow the binding of food pieces into reconstituted food $[12,16]$. The increasing awareness of problems with food allergy and intolerance has led to the requirement to state the source of certain emulsifiers on food labelling. For example, lecithin derived from soya is not suitable for an individual with an allergy to soya, therefore clear labelling of the source of the ingredient is vital to aid in consumer choice of products safe for individuals with specific dietary requirements.

Colours: Colours are used to enhance the visual properties of foods. Colour is important in consumer perception of food and often denotes a specific flavour [12, 16, 25]. Their use is particularly controversial, partly because colour is perceived by some as a means of deceiving the consumer about the nature of the food, but also because some of the most brightly coloured products are those aimed at children. As with all additives, their use is strictly controlled and permitted only where a case of need is proven, e.g. to restore colour that is lost in processing, such as in canning or heat treatment; to ensure consistency of colour; and for visual decoration. The brilliant yellow of saffron (from which Saffron Walden derives its name) and the reddish hue of saunders (powdered sandalwood) were used along with green spinach and parsley juice to colour soups in stripes or to give marbleised effects [19]. So, whilst adding colour to food may appear to some to be an unnecessary cosmetic, which is not in the consumer's interests, there can be no doubt that the judicious use of colour enhances the attractiveness of many foods. Some retailers tried introducing ranges of canned vegetables and fruits such as strawberries and peas without adding back the colour leached out by heat processing. They were still trying to dispose of the unsold returns several years later! Colour is important in consumer perception of food and often denotes a specific flavour. Thus, strawberry flavour is expected to be red and orange flavour orange-coloured. Consumer expectation is therefore a legitimate reason for adding colour. Food colourings, in particular, have long been the scapegoat in the popular press for behaviour problems in children. It has been over 30 years since Feingold suggested that artificial food colours and preservatives had a detrimental effect on the behaviourof children [13].

Since then, research into the effect of colours and preservatives in foods on children's behaviour has added fuel to the fire of negative consumer perception of these additives, particularly in products aimed specifically at this age group. Significant changes were found in the hyperactivity behaviour of children by removing colorants and preservatives from the diet. There was no gender difference in this result and the reduction of hyperactivity was independent of whether the child was initially extremely hyperactive, or not hyperactive at all.

Colouring: Foodstuffs The term 'colouring foodstuffs' has been adopted for colourings that are derived from recognised foods and processed in such a way that the essential characteristics of the food from which they have been derived are maintained. This is a different situation to natural colours that are regarded as additives where the pigment is selectively extracted and concentrated. A colouring foodstuff can be declared as an ingredient on the label without a requirement for its function to be listed, as legislation only requires this of additives.

These colouring foodstuffs include bright yellow colours derived from turmeric, oleoresin and safflower; golden yellow to natural orange colours from carrots and paprika; toffee brown colour from caramelised sugar syrup; green colours from spinach leaves and stinging nettles, both rich in chlorophylls; and red, blue and purple colour from concentrates of red and blue fruits, red cabbage and beetroot, rich in anthocyanins. It is clear that the full spectrum of colour shades is achievable using colouring foodstuffs, although developers should ensure that the colouringfoodstuff exhibits the same stability and vibrancy of colour in the final application as a conventional food colouring would.

Flavor enhancers: Flavor enhancers enhance a food's existing flavors. They may be extracted from natural sources (through distillation, solvent extraction, maceration, among other methods) or created artificially $[15,16]$. They can be incorporated in to different types of food and food products. Some of common flavor enhancers used are Dioctylsodium sulfosuccinate-used in processed foods, Disodium guanylate-used in canned meats, meat based foods, Hydrolyzed vegetables-used in mixes, stock, processed meats and Monosodium glutamate (MSG)-used in Chinese food, dry mixes, stock cubes, and canned, processed, and frozen meats.

Food Processing aids in industrial food biotechnology: an overview

\section{Overview to Food processing aids}

Food processing aid as a substance that is used for a technical effect during food processing or manufacture/facilitating the production process but, unlike food additives, its use does not affect the intrinsic characteristics of the food and it results in no 
or negligible residues of the substance or its by-products in or on the finished food. A processing aid is a substance used in the production of processed food, and which may end up in the finished product, but which is not required to be labeled on the food product. Our Food Experts can offer you the right products to optimize your processing conditions. Products that can support here as processing aids are: Antifoams; enzyme(s) and free flowing agents.

The use of antifoams and free-flowing agents is sometimes necessary, to either control the production process or maintain properties during storage. Enzymes are also in most cases processing aids; being active during the production process and being inactivated in the final food product. Enzymes influence the yield, capacity or efficiency of food manufacturing processes, but also influence end product properties. Processing conditions, food composition (substrate) and required action are the selection criteria for choosing the correct enzyme. Application of enzymes in baking, beer brewing, alcohol production and fruit processing are well known but novel applications of enzymes are under development.

Antifoams: Antifoams are also known as "defoamers." These additives serve businesses across a number of industries by helping to maintain foam formation or stopping bubbles from occurring in production operations. The ingredients are insoluble in foaming mediums and spread rapidly across surfaces due to their low viscosity. The need for antifoams becomes apparent when foam disturbs processing, filling or volume measurements or when the texture of the food product is negatively affected. The first solution to prevent foam is control of the processing but in some cases food manufacturers cannot do this without the addition of antifoam.

Antifoam applications in food industry: Defoamers cut back on material losses during food preparation and production. Antifoaming agents of the silicon-base variety are common within the food industry to meet customer expectations of products. Food professionals see defoamers in the preparation of deep-fried foods such as chicken nuggets, fries, and chips.

The additives give food companies the opportunity to enhance methods for: Washing food products (vegetables) Antifoam applications in food industry; Distillation and evaporation; Packaging; Extraction; Purification; Crystallization.

Free Flowing Agents: Free flowing agents are commonly known as anticaking ingredients across the food industry. They are included in products to keep powders, sugar, salt, and other granulated mixtures from clumping together during preparation and production.

Applications for free-flowing agents in food industry: Companies working with the following food products might need free flowing agents to avoid the formation of lumps in production stages or on storage: Table salt; Soup powders; Flour; Coffee; Teas; Baking mixtures; Milk powders; Creamers; Grated cheese and Powdered sugar.

Enzymes: Enzymes play complex roles in food production as well as general human health and nutrition. In simple terms, their job is to speed up chemical reactions. For example, digestive enzymes in the stomach, mouth, and small intestine help break down food, facilitating the absorption of nutrients into the body. Over the years, humans have harnessed the power of different enzymes for a variety of food applications. Enzymes for example facilitate the fermentation process when making beer, yogurt, and cheese. Applications for enzymes: Enzyme manufacturers produce enzymes from plant, animal, and microbial sources for use in vegetable and fruit processing, baking and milling, craft brewing and distilling, winemaking, and dairy and cheese processing, among other applications. Each enzyme has a unique three-dimensional shape with a highly specific reactive capability.

Biotechnological products (micro-organisms themselves or products from them) can be used as processing aids in manufactured foods. Enzymes in particular are extremely useful in modifying the characteristics of food ingredients, so that the food has improved taste, texture and keeping qualities. Microbial products other than enzymes are used as flavours, sweeteners, thickeners and acidulants. Those several role food industrial biotechnologies for food Processing aids includes, the roles of enzymes in preparation of bakery products; production of cheese and enzyme-modified cheese; whey modifications; meat tenderization; interesterification of oils and fats; natural food-preservation systems; the production of invert sugar; and also, the biotechnological production of organic acids; and the biotechnological production of flavours.

\section{Role of Enzymes as Food Processing Aids}

Essential in the metabolism of all living organisms, the enzymes are increasingly used to drive chemical reactions outside their natural localization. In particular, the use of the biocatalysts as food additives and in processing raw materials has been practiced for a long time. In fact, enzymatic preparations from the extracts of plants or animal tissues were used well before much was known about the nature and properties of enzymes. Food industry is constantly seeking advanced technologies to meet the demand of the consumers, and enzymes have long been used by the industrial product makers as major tools to transform the raw materials into end-products. Their clean label (generally recognized as safe) consideration from the legal point of view has prompted their extensive use in food technology. When purified and added to food preparations, several enzymes are able to improve their flavor, texture, digestibility, and nutritional value.

Enzymes are used extensively in food production and processing. The ones most widely applied are amylases, glucose oxidases, proteases, pectic enzymes, and lipases. Excellent reviews on the production and utilization of food enzymes are available. Immobilized enzymes and immobilized whole cells have received significant attention as valuable biocatalysts for the food processing industry. The advantages of the application of immobilized systems include continuous operation, reuse of the biocatalyst, ease of process control, improved biocatalyst stability, and reduced waste disposal problems [4]. Immobilized biocatalyst technology also can be applied successfully to the production of secondary plant metabolites [5]. In addition, the production of enzymes with enhanced stability to temperature and other processing conditions is receiving much attention [7]. The significant impact that biotechnology can have on the production of a food ingredient is exemplified by the development of high-fructose corn syrup technology. 
Table 1. Food processing aids and industrial application or product type.

\begin{tabular}{|c|c|c|}
\hline $\begin{array}{c}\text { Processing } \\
\text { Aids }\end{array}$ & Processing/products & Function \\
\hline \multirow{5}{*}{ 1.Enzymes’ } & Wine Making & $\begin{array}{l}\text { Decreases viscosity and filtration time; Increases press yields; Improves set- } \\
\text { tling and enhances clarification; Improves deleptonization and the extraction } \\
\text { of tannins and aromas; and extracts more color. }\end{array}$ \\
\hline & $\begin{array}{l}\text { Fruit \& Vegetable Pro- } \\
\text { cessing }\end{array}$ & $\begin{array}{l}\text { Faster and more efficient juice extraction from apples and pears; Delepton- } \\
\text { ization and haze clarification of juices; Maceration and color extraction of } \\
\text { grapes and berries; Cloud stability for citrus juices; Juice clarification of stone } \\
\text { and tropical fruits; and De-bittering of fruit juices Improving throughput and } \\
\text { membrane cleaning. }\end{array}$ \\
\hline & $\begin{array}{c}\text { Dairy \& Cheese Process- } \\
\text { ing }\end{array}$ & $\begin{array}{c}\text { Improved amino acid production and fat hydrolysis for cheese flavor en- } \\
\text { hancement; Improves yield, taste and texture of cheese; Aids in the produc- } \\
\text { tion of cheese with consistent quality and reduced bitterness; Helps make } \\
\text { cheese with smooth and velvety texture; and Lactose reduction for milk, } \\
\text { cheese, and ice cream. }\end{array}$ \\
\hline & Craft Brewing \& Distilling & $\begin{array}{l}\text { Easier, faster and more consistent processes; Improves steeping, brewing, } \\
\text { cooking and germination; Improves mashing and yeast nutrition; More flexi- } \\
\text { bility in the choice of raw materials; More extraction from raw materials; and } \\
\text { improves the quality of final products. }\end{array}$ \\
\hline & Baking \& Milling & $\begin{array}{l}\text { Creates prolonged softness; Increases dough handling, volume and soft- } \\
\text { ness; Improves dough strengthening, whiteness, finer crumb structure and } \\
\text { crust color; Gluten correction in biscuits and wafers; Egg reduction in cakes; } \\
\text { Emulsifier replacement. }\end{array}$ \\
\hline \multirow{4}{*}{$\begin{array}{l}\text { 2. Free } \\
\text { Flowing } \\
\text { Agents }\end{array}$} & \multirow{2}{*}{ Stearates: } & $\begin{array}{l}\text { Magnesium and Calcium stearate exist as a fine powder for foods and dietary } \\
\text { supplements. Consisting of stearic acid and magnesium or calcium, the com- } \\
\text { pound acts as a lubricant in the separation of mixtures and ingredients. }\end{array}$ \\
\hline & & $\begin{array}{l}\text { Stearates assist in controlling the consistency of foods so hat components do } \\
\text { not stick together throughout production and packaging. Both magnesium } \\
\text { and calcium stearates can also be used as a lubricant in tableting processes. }\end{array}$ \\
\hline & Silica (silicon dioxide) & $\begin{array}{l}\text { The ingredient can be found naturally within plants and water. For powdered } \\
\text { foods, food formulators can include silicas as anticaking agents. This ingredi- } \\
\text { ent extends free flowing capabilities for a wide range of food products. Silica } \\
\text { is one of the most effective free flowing agents. }\end{array}$ \\
\hline & Tricalcium Phosphate & $\begin{array}{l}\text { Tricalcium phosphate is used as a mineral for phosphate and calcium forti- } \\
\text { fication. It is used as a carrier in tablets and it can also act as a free-flowing } \\
\text { agent }\end{array}$ \\
\hline \multirow{2}{*}{ 3.Antifoams } & Oil-based foam control & $\begin{array}{l}\text { Oil-based defoamers are ideal for intense foaming applications and reduc- } \\
\text { tion. They contain an oil carrier and do not mix well with water for optimum } \\
\text { antifoaming characteristics. These antifoamers are insoluble in water and } \\
\text { water-based solutions. }\end{array}$ \\
\hline & Silicon-based defoamers & $\begin{array}{l}\text { Silicon-based antifoams feature a hydrophobic form of silica for remaining } \\
\text { insoluble in water. Food manufacturers can utilize silicon-based antifoams in } \\
\text { food preparation, water treatment, and more. These ingredients can also be } \\
\text { found in non-aqueous foaming systems, including oil refining. }\end{array}$ \\
\hline
\end{tabular}

Bakery products: Flour, yeast, water and salt are the basic ingredients of bread and other similar baked foods. For centuries it has been common to add other materials that have a positive effect on the handling of the dough and/or the quality of the baked product.

Fats, emulsifiers and oxidising agents can affect bread texture. Fats, oxidising agents, reducing agents and soya flour can affect the speed of bread making. The ingredients are not really added to increase the food value, even though they might do so (for example soya flour). Enzymes either from malt or micro-organisms play an important role and function in addition to the endogenous enzymes. Their functioning is best illustrated by describing their involvement in the various phases of bread making i.e., mixing, fermentation, baking and storage of bread.

Fruit and vegetable juices: In addition to clear and cloudy fruit juices, the main industrial products today are concentrates. Since the manufacturer of fruit juices wants to deliver products with a constant quality all year round, and since the supply of fruit is seasonal, the harvested fruits are, after storage in cold warehouses, processed into stable concentrates. Usually, the concentrates are sold to the actual juice manufacturers who dilute and pasteurise the juices before delivery to the customer. Enzymes have found 
wide application in the production of fruit juices in a number of ways: for clarification of juices; to improve the pressing yield of the fruit; to overcome filtration problems; to increase the liquefaction rate of fruits; to improve the colour and flavour extraction; in the case of vegetable juice, to enable the total lique faction of vegetable material.

Dairy products: The use of enzymes for the processing of milk into cheese is one of the earliest examples in history of the application of enzymes in food technology. Thousands of years ago it was found that milk which was stored in a bag made of the stomach of a recently killed calf was converted into a semi-solid substance. Upon pressing, this substance produced a drier material which showed good keeping qualities. This process has evolved into the production of a wide variety of cheeses.

Apart from the proteolytic enzymes which are used to manufacture cheese, other enzymes which are active on milk sugar (lactose) or on milk fat, have been developed in the last two decades. Enzyme-modified cheese,Proteases and lipases from different micro-organisms are used for the production of cheese flavours.

The tenderization of meat: Tenderness is a desirable quality of meat. Endogenous enzyme activity (neutral protease and collagenase) is the main factor contributing to the development of tenderness, ie to the conversion of muscle into meat.

On a commercial scale, plant proteases such as papain (from papaya) and bromelain (from pineapples) are used. These proteases are capable of digesting connective tissue and muscle protein. A practical problem is how to achieve even distribution of the enzymes in the tissue. If preparations are sprinkled on the surface of the meat, the interior of the meat remains tough. Repeated injection under pressure into the meat is another possibility. Intravenous injection a few minutes before slaughtering has also been studied. In most countries treatment of meat with exogenous enzymes is controlled by legislation.

The modification of oils and fats: The major components of oils and fats are triglycerides, and their physical properties depend upon the structure and distribution of their fatty acid groups. Natural oils and fats can be used directly in products either individually or as mixtures, but in many cases it is necessary to modify their properties, particularly their melting characteristics, to make them suitable for particular applications.

Therefore, the oils and fats industry has developed processes which modify the composition of triglyceride mixtures. For example, fractional crystallisation is used to separate fats into solid and liquid fractions, and hydrogenation is used to reduce the unsaturation of fats (thereby raising their melting points). Chemical interesterifkation is used to change the physical properties of mixtures of fats by randomly redistributing fatty acid groups among the triglycerides.

The potential advantages of using enzyme technology (compared to conventional chemical and physical procedures) are found in the specificity of enzyme catalysis and the mild reaction conditions under which enzymatic processes are operated. Enzyme catalysed reactions can be operated without the generation of byproducts associated with the use of more severe chemical procedures, giving improved product yields and/or better product qual- ity. The specificities of the enzymes can be exploited to generate products which are difficult to obtain by chemical procedures.As well as being active, the chosen immobilised enzyme also needs to be stable (active for a long period) and the support must promote this. The support must also have appropriate mechanical characteristics: it should not disintegrate if used in a stirred tank reactor; it should produce even flow (without channelling) in a packed bed reactor. The cost of the support is also important.

Natural preservation systems: Throughout history the problem of food spoilage has plagued man. Early attempts to preserve food centred on readily available substances and processes, such as using sugars, salts (lowering water activity, Aw), spices and wood-smoke. Today preservation also utilises such factors as: temperature (sterilisation, cooling, freezing); lowering water activity (drying); adjustment of $\mathrm{pH}$; gases (CO, CCh, ethylene oxide, propylene oxide, sulphur dioxide and ozone); organic acids (sorbic, acetic, benzoic, lactic, propionic acid); antibiotics; irradiation; packaging; various additives (formaldehyde, monochloroacetic acid, borates, nitrite, sulphite); various combinations of these factors. While these factors have ensured a constant supply of unspoiled food, there is a reaction against addition of chemical preservatives to food amongst many consumers. There is thus interest in developing preservation techniques which can be promoted as being 'natural'.

Although the use of anti-microbial proteins and peptides is not widespread as yet, we are going to examine them here to emphasise their possibilities in natural preservation systems.

Enzymes/proteins can function as anti-microbials in several ways, such as: depriving spoilage organisms of an essential nutrient; generating substances toxic to spoilage organisms; attacking a cell wall/membrane component, thereby physically disrupting the cell or changing the permeability of the cell wall/membrane (iemicrobicidal substances).

\section{Sweeteners}

Invert Sugar: Cane and beet sugar can be converted to a 1:1 glucose: fructose mixture (called invert sugar), either by acid hydrolysis or by enzymatic hydrolysis (since sucrose is a disaccharide composed of one molecule of glucose and one molecule of fructose). The enzyme responsible for the hydrolysis of sucrose is called invertase. The virtue of invert sugar as a food ingredient compared to sucrose are: its higher solubility (and lower tendency to crystallise in concentrated solutions); and its stability at low $\mathrm{pH}$, and the enhancement of fruit flavours and higher sweetness due to the fructose present.

Alternative sweeteners: A large number of alternative sweeteners have been developed during the last 25 years. Lately the demand for low-calorie sweeteners has increased considerably, particularly in the soft drinks industry. Also, the manufacturing processes vary considerably, for example thaumatin is a protein extracted from plants (see later), aspartame is a dipeptide synthesised by chemical or enzymatic methods and saccharin is chemically synthesised.

Aspartame: dipeptide consisting of L-aspartic acid and the methylester of L-phenylalanine, is an example of an alternative sweetener which, since it was approved for use in soft drinks by the 
FDA (Food and Drug Administration, USA) in 1983, has gained a rapidly increasing market share. The specificity of enzymes in catalysing the formation of aspartame from its constituent amino acids offers three advantages. These are: the use of ambient conditions instead of highly energy-intensive (refrigerated) systems; the use of racemic reactants which are cheaper than optically pure amino acids; and there is no need to block the side-chain carboxylic group.

\section{Production of flavours}

Flavour is a very important component of the consumer's appreciation of a food, contributing to its smell and taste and interacting with the mouth feel and colour of thefinal products of food. Developments will be in the use of microbes and their enzymes (i.e., Prospects, Flavour precursors, Flavour enhancers) in synthesis and conversion of flavour compounds.

\section{Biopolymers}

Biopolymers such as proteins and polysaccharides that are used as food ingredients generally have the property of easily dissolving or dispersing in water. These hydrocolloids' are often used as thickeners (gelling agents), viscosifiers, emulsifiers or fillers. Commercially available proteins used as food additives are derived from both plants and animals. Plant sources are soya beans, cotton seed, sunflower seed, rapeseed and ground nuts (peanuts). They are often produced as by-products of oil extraction and are produced as flour (about 50\% protein), as concentrates (about $65 \%$ protein) and as isolates (about $90 \%$ protein). Animal sources of protein are milk (casein and whey proteins), bones (gelatin), blood and eggs.

Biotechnology may have applications in the improvement of such proteins by: increasing the level of essential amino acids; removing anti-nutritional factors (such as trypsin inhibitors); modifying the properties of the protein by proteases to allow easier processing (eg processing at lower temperature).

\section{Amino acids}

The application of amino acids in food can serve different purposes: as flavour enhancers, as seasonings, as nutritional additives and occasionally as improver ingredients (in bread).

\section{Organic acids}

As with the production of amino acids, organic acids can be produced by chemical synthesis, by fermentation or by extraction from natural products. Enzymatic synthesis is not employed in the case of organic acids. Fermentative production is restricted to citric acid, gluconic acid, lactic acid and itaconic acid.

In volume, citric acid, which is exclusively produced by fermentation, is by far the most important organic acid, accounting world-wide for over 350000 tons annually. Citric acid is generally produced by the fungus Aspergillus niger or the yeast Candida lipolytica, grown on molasses or other cheap carbohydrate sources. Yields on sugar up to $85 \%$ have been reported. Citric acid is used in food products to enhance the flavour, to prevent oxidation and browning, and as a preservative as a result of the $\mathrm{pH}$ lowering. It is also used as a raw material for chemical synthesis and for pharmaceutical purposes.

\section{Vitamins}

Vitamins are chemicals which are essential, in small amounts, for growth and development of living organisms. If they cannot be synthesised by the organisms, they must be taken up in the diet. Vitamins are used mainly as dietary supplements and intherapeutic applications. The exception is vitamin C (ascorbic acid) which is also usedas a food ingredient. As a result of its relatively strong reducing power, it is used widely in food as an antioxidant and as an antimicrobial agent.

Can you think of a way in which vitamin $\mathrm{C}$ acts as an antimicrobial agent? (The clue is in its strong reducing ability). Obligate aerobic bacteria (which may be associated with food spoilage) grow best is an environment in which there are chemically oxidised molecules. Such an environment is said to have a high redox potential (written as Eh or O.R. potential). Oxidising compounds such as nitrite can stimulate the growth of such bacteria. Reducing agents such as ascorbic acid can depress the growth of such bacteria.

\section{Food additives/processing aids and the role of industrial food biotechnology in food processing}

Industrial food Biotechnology in food processing can significantly affect food product composition, quality, and functionality by providing tools for product modification, preservation, and stabilization, as well as for safety, characterization, and quality control. In addition, processing methods, especially separation and fermentation processes and waste treatment and utilization can contribute to the improvement of food products.

\section{Product modification}

Significant advances have been made in the modification of food components, such as proteins, polysaccharides, fats, and oils. Protein modifications, for example, include limited enzymatic hydrolysis to alter food functionality; the reverse process, the socalled plastein reaction, has been proposed as a method to create proteinlike materials to develop new food products. Modification of properties of proteins by combining information on crystal structure and protein chemistry with artificial gene synthesis is also being explored [5].

\section{Product preservation}

Historically, there has been extensive use of microbial metabolism for food preservation and stabilization, especially for dairy, meat, fish, fruit, and vegetable products. The efficiency of microorganisms used in the food fermentation industries potentially can be enhanced by genetic manipulation of starter cultures. However, additional fundamental knowledge of the genetics, biochemistry, and molecular biology of organisms used as starter cultures is required [7].

\section{Product safety, characterization, and quality control}

Besides the use of classical methods to ensure the quality and safety of food and to identify food components [1], three recent developments are relevant to product safety, characterization, and 
quality control: (i) the potential application of monoclonal antibodies to determine optimal crop harvesting and product freshness, (ii) the use of biosensors and DNA hybridization techniques for quality control and (iii) the potential of tissue culture and genetic methods for nutrient and toxicity assessment. In addition, the regulatory and safety aspects of biotechnology and their impact on the nutritional quality of the resulting food products are being examined [11].

\section{Processing methods}

Mechanical unit operations used for product purification and recovery include sedimentation, centrifugation, and filtration, along with dialysis, flotation, and ultrafiltration [24]. Biomass separation is commonly aided by bio-flocculation or by the use of synthetic polyelectrolytes. Recently, natural polyelectrolytes such as chitin and chitosan have been investigated as substitutes for synthetic polyelectrolytes. Application of aqueous two phase (liquid-liquid) systems for the extractive purification of enzymes and the supercritical extraction of food ingredients are becoming increasingly important. In supercritical extraction, carbon dioxide is favored as the dense gas because it is nontoxic, nonexplosive, cheap, readily available, and easily removed from extracted products. In addition, co-fermentation processes have been suggested to aid the separation and purification of secondary metabolites [4].

\section{Treatment and utilization of process waste}

Because of the large volumes involved in the production and processing of food, generated wastes create disposal and pollution problems. In addition, there is a substantial loss of essential nutrients.

Biomass recovery, especially isolation of valuable protein byproducts, has been carried out in the food processing industry for an extended period of time. The isolation of protein concentrates from potato processing wastes, for example, has been used on an industrial scale for several decades, and the product's potential for food application has been investigated extensively. During the past decade, ultrafiltration has become useful in food processes, especially for the recovery of whey protein from cheese, cottage cheese, or industrial casein processing wastes. By product recovery has also been explored for application to the processing of meat, cereal, dairy, fruits and vegetables, and fish and shellfish, as well as fermentation operations [10].

\section{Needs for Research}

Faster innovation, particularly in the development of agricultural raw materials, is possible, allowing for the maintenance of a competitive worldwide position. Also envisaged are lower energy use in food processing and the availability of an added value use for agricultural commodities that are now in abundance.The initiatives listed below address research needs at various points along the process from agricultural production to consumer:

\section{Improvement of food-grade microorganisms}

Microorganisms-bacteria, yeasts, and fungi-are all used extensively in various aspects offood processing. To improve the economics (yield and productivity) and new product characteristics achievable with these organisms, major advances are needed in our understanding of their biochemistry and genetics. Specific research needs are (i) to establish recombinant DNA technologies and a fundamental understanding of microorganisms useful in food fermentation and preservation processes; (ii) to quantitatively describe the microbial ecology and biochemistry of mixedculture and solid-state fermentations important in foodstuffs; (iii) to isolate, select, and genetically manipulate organisms capable of synthesizing food additives such as biopolymers, colorants, natural flavorings, and preservatives-by fermentation and cell culture; and (iv) to develop economically viable bioprocesses as sources of raw materials for the food processing industry.

\section{Cell physiology and biochemistry of agricultural raw ma- terials}

The potential exists to lower the cost of agricultural raw materials, both plant and animal, by application of biotechnological techniques. Potential targets for improvement are (i) solids content, sensory properties (color, flavor, texture), environmental adaptation, secondary metabolites (vitamins), and postharvest storability in crops and (ii) feed efficiency, palatability, fat/protein ratios, fertility, and maturation time of juveniles in animals.

To realize these benefits, a vast increase is necessary in our understanding (at the molecular level) of the cellular physiology, including biosynthetic and regulatory pathways, of the appropriate animal and plant species.

\section{Application of biotechnology to the structural-functional re- lationship of food material}

This program aims to improve the utilization of biomaterials by applying modern biotechnological principles to control the functional performance of foodstuffs. In addition, biotechnology will contribute analytical tools and processing procedures that will aid in the implementation of this new knowledge.

\section{Improvement of enzymatic processing}

Enzyme processes can reduce the high cost of traditional food processes and also permit development of totally novel foods and food ingredients. To expand the range of possible processes and to improve on the economics of current enzyme-based processes, increased basic knowledge is needed on enzyme isolation and characterization, the mechanisms of enzyme action, and enzyme incorporation into food processes. Specific needs are to understand the mechanisms of enzyme inactivation; toutilize enzymes for biosynthetic processes and redox reactions relevant to foods, including the low-cost production and recycling of cofactors; and to develop new process procedures using immobilized whole cells. Fundamental studies are needed on the control of mass transfer in food systems, maintenance of catalytic activity, and prevention of contamination. Also needed are computer modeling and understanding of the mechanisms of action of food processing enzymes in sufficient detail to permit systematic protein engineering to improve enzymes.

\section{Methods development}

To improve the production costs, nutritional value, and cost in use of some of the major agricultural crops, particularly cereals, fur- 
ther fundamental advances in cell culture methods and recombinant DNA technologies are necessary. Specific research needs are (i) vector development and transformation procedures for cereal crops, (ii) improved regulation and expression of foreign genes, and (iii) techniques to regenerate and propagate crops that cannot now be so handled. To reduce the time and cost of developing new crop species, rapid screening methods are required to identify the desired genotype at the cell culture stage.

\section{Food safety}

There is an urgent need to improve and to accelerate techniques of food safety assessment. Biotechnology can contribute to food safety by increasing the sensitivity and specificity of such assays and by developing faster and more meaningful methodologies based on DNA hybridization, sequencing, and monoclonal antibody techniques. The most critical research needs, in addition to basic studies on the structure-function relationship of food materials, are fundamental studies in the cell physiology and biochemistry of agricultural raw materials and improvement of food-grade microorganisms.

\section{Conclusion}

Food additives are substances that are intentionally added to food either during the production process or at packaging with the purpose to increase food safety and durability, to improve or restore food organoleptic characteristics and attractiveness and, in some cases, to improve the technological performance during the transformation process. Food additives are substances that have an effect on the final product and remain subject to the general labeling obligations. The consumption of processed food is more and more frequent for many reasons, among which is less available time for meals preparation at home. The way of purchasing food supplies is rapidly changing and foodstuffs are kept in refrigerators at home for longer times not always at suitable temperatures. All types of foodstuffs are requested in any season, often coming from different continents with long transport time at temperatures sometimes unsuitable or even not well controlled hence, the need of food products having longer and longer shelf lives while assuring the respect of high food safety standards. In such cases, the simple compliance with keeping temperatures and good manufacturing practices may not be sufficient to guarantee the product stability or its attractive appearance. Although consumers are aware of the relationship between food and health and prefer foods with a short list of ingredients and labelled as "clean" as possible, the addition of additives is sometimes necessary to ensure food safety and to allow consumers to benefit from safer and more attractive foods, with longer shelf-lives and sold at a reasonable price.

However, additives should be used sparingly, and there must be a technological need and a benefit for consumer for their use. If used, additives must not mislead consumer about the nature, freshness, quality of the ingredients used, the product naturalness or the production process, or the nutritional quality of the product, including its fruit and vegetable content. In other cases, the technological advances in food industry, such as the application of new technological processes allowing food transformation process without significant damage to its structure and organoleptic characteristics, the use of new packaging materials and controlled atmospheres, and the possibility of keeping foodstuffs under strict cold chain for their entire shelf life are useful means to limit the use of additives to a minimum.

Processing aids are substances intentionally used in processing raw materials, foods, or their ingredients, to fulfil a specific technological purpose. Eventual residues in the final product shall neither have any functional effect on the final product nor constitute a health risk for the consumer or become a precursor to food alteration. Processing aids must have a high degree of purity. Some substances, when used as processing aids, could have the identical chemical structure of the additives, but in specifically circumstances perform a different function. Label declaration of processing aids is not obligatory. Functional classes of processing aids can be distinguished as follows: Solvents for oils and fats extraction; Solvents for spices, drugs, and herbs vehiculation; Organic and inorganic clarifying agents (food enzymes included); Ion exchange resins for drinking water and process water; Deodorization and discoloration materials for oils and fats; Filtration supports (tissues, diatomaceous earth, silica sand, vegetable, and synthetic fibers); Detergents and disinfectants; and Defoamer agents.

The food industry serves the function of supplying us with high quality, wholesome foods, all the year round and at a distance (in time and location) from the place of primary production (where the food was grown). To achieve this, good logistics of distribution and preservation methods such as refrigeration and deep freezing are employed. However, much of our food is processed in order to preserve it, make it more convenient to cook, to improve its organoleptic qualities, or to create alternative foods. In processing, use is frequently made of food additives and food processing aids, which are specific ingredients which in some way help to preserve or improve the quality of the processed food.

\section{References}

[1]. A Kramer, BA Twigg. Quality Control for the Food Industry. AVI: Westport, Conn, 1970.

[2]. Aderemi AV, Adeloye D, Aderemi MA. Food additives and their health implications on children in Africa: a systematic review. Res J Health Sci. 2015;3(1):1-2.

[3]. Al-Mazeedi HM, Regenstein JM, Riaz MN. The issue of undeclared ingredients in halal and kosher food production: A focus on processing aids. Comp Rev Food Sci Food Saf. 2013 Mar; 12(2):228-33.

[4]. B. Dixon, Biotechnology 2, 594 (1984); D. Knorr, S. M. Miazga, R. A. Teutonico, Food Technol., in press.

[5]. B. H. Kirsop, Chem. Ind. 7, 218 (1981); J. W. Lee and A. Lopez, CRC Crit. Rev. Food Sci. Nutr. 21, 289 (1984); K. M. Ulmer, Science 219, 666 (1983).

[6]. Branen, A. and Haggerty, R.J. 2002. Food additives (2 nd Ed). New York Basel. ISBN: 0-8247-9343-9.

[7]. C. A. Batt and A. J. Sinskey, paper presented at the Symposium on the Importance of Lactic Acid Fermentation, Mexico City, December 1984.

[8]. Department of human nutrition. 2010. The role of food additives. Nutrition News. KSTATE Research and extension. Retrieved June 20, 2017, from: http://www.doughlas.k-state.edu/docs/health nutrition/food add roles.pdf

[9]. Directive 89/107/EEC on the approximation of the laws of the Member States concerning food additives authorised for use in foodstuffs intended for human consumption, as amended.

[10]. D. Knorr, in Sustainable Food Systems, D. Knorr, Ed. (AVI, Westport, Conn., 1983), pp. 249-78.

[11]. E. L. Korwek, Food Drug Cosmetic Law J. 37, 289 (1982); D. D. Jones, Food Technol. 39 (No. 6), 59 (1985).

[12]. Emerton V, Choi E. Essential guide to food additives. Royal Society of Chemistry; 2008.

[13]. Feingold B.F. Hyperkinesis and learning disabilities linked to artificial food 
flavors and colors. American Journal of Nursing. 1975;75:797-803.

[14]. Ghoshal G. Biotechnology in food processing and preservation: an overview. Advances in Biotechnology for Food Industry. 2018 Jan 1:27-54.

[15]. Japans External Organization. 2010. Specifications and standards for foods, food additives, etc. under the Food Sanitation Act. Retrieved/ from June 24, 2017, from: http://www.jetro.or.jp regulations/pdf/foodext2010.pdf

[16]. Jie M. Chinese Standards for Food Additives-GB2760-2015. Global agricultural information network. Giant report number (FAIRS). 2015;15013:1034.

[17]. Lee, J.K. 2012. Regulatory frameworks of food additives in Korea. International Conference for sharing information on food standards in Asia. Hanyang Women's University.

[18]. Maryam BM, Datsugwai MS, Shehu I. The role of biotechnology in food production and processing. Industrial Eng. 2017;1(1):24-35.

[19]. McKendry M. Seven Hundred Years of English Cooking. London, Treasure Press. 1973.
[20]. Pal M, Patel AS, Bariya AR, Godishala V, Kandi V. A review of biotechnological applications in food processing of animal origin. Am J Food Sci Tech. 2017 Aug 2;5(4):143-8.

[21]. The Official Journal of the European Communities. 1989, 32 (L40), 27-33.

[22]. Codex Alimentarius Commission, Guidelines on Substances used as Processing Aids: CAC/GL 75- 2010

[23]. Food and Drug Administration USA. Everything added to food in the United States. Smoley; 1993.

[24]. V. Wiesboden and H. Binder, in Advances in Biochemical Engineering, A. Fiechter, Ed. (Springer Verlag, Berlin, 1982), pp. 120-171.

[25]. WHO. 2009. Safety evaluation of certain food additives/prepared by the sixty-ninth meeting of the Joint FAO/WHO Expert Committee on Food Additives (JECFA). World's Largest Science, Technology and Medicine Open access Book publisher. WHO Food Additive series 60.ISBN 97892 4 1660600, India, pp. 10-15. 